\title{
BIPOLAR DISORDER AND MEDICAL ILLNESSES: COMORBIDITY IN AN AMBULATORY MENTAL HEALTH CENTRE SAMPLE
}

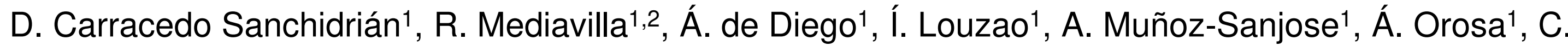 \\ Rocamora1, M.P. Vidal-Villegas¹, C. Bayón1, M.F. Bravo1, B. Rodriguez¹, G. Lahera3,4, C. de Dios¹. \\ ${ }^{1}$ Hospital Universitario la Paz, Psychiatry- Clinical Psychology and Mental Health, Madrid, Spain \\ ${ }^{2}$ National University of Distance Education UNED, Faculty of Psychology, Madrid, Spain. \\ 3Universidad de Alcalá, Mental Health, Alcalá de Henares, Spain. \\ ${ }^{4}$ CIBERSAM, Mental Health, Madrid, Spain.
}



\section{Objective}

To determine the magnitude of comorbid medical illnesses with bipolar disorder in outpatients.

\section{Background}

Patients with Bipolar Disorders diagnosis are at increased risk for comorbid medical illnesses (McIntyre, Konsarski and Soczynska, 2006). In the Unites States about 32 percent of patients have one general medical condition, being the most prevalent Arthritis, Back pain, Cardiovascular diseases, Chronic obstructive pulmonary disease and Diabetes (Perron, Howard y Nienhuis, 2009). The implications of this high comorbidity for the treatment are discussed in this work.

\section{Materials and Methods}

A sample of 84 outpatients with well-established diagnosis of Bipolar Disorder was analyzed. The sample appertains to patients with psychiatric follow-up in public Mental Health Centre in Spain. The comorbid medical illness was inquired both clinical medical history and in interview.

\section{Results and Conclusion}

In 35 of the 84 outpatients at least one general medical condition was present, which is a 41.7 percent. The most frequent disease was Endocrine, nutritional and metabolic diseases, and immunity disorders (ICD-9 codes 240-279), that supposed a 30.6 percent. Other relevant diseases were Diseases of the musculoskeletal system and connective tissue (ICD-9 codes 710-739) with a 18,1 percent and Diseases of the circulatory system (ICD-9 codes 390-459), with a 11,1 percent.

Comorbidity is a frequent conjuncture and the medical illnesses that come up with Bipolar Disorder complicate the treatment and follow-up. Comprehensive multidisciplinary intervention is needed in order to provide the best treatment as possible, keeping in mind the chronicity of this disorder.

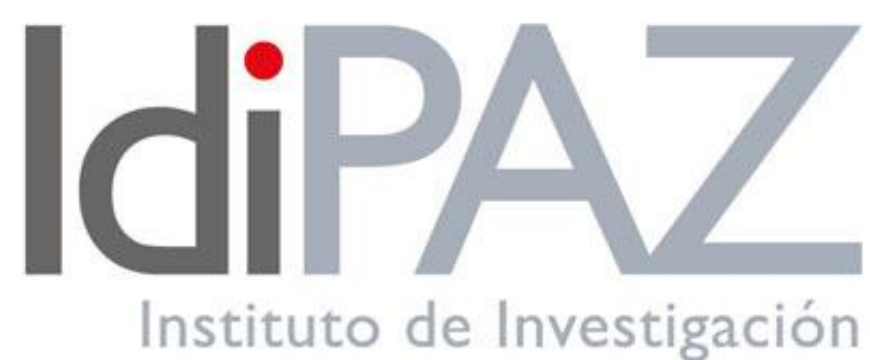
Hospital Universitario La Paz

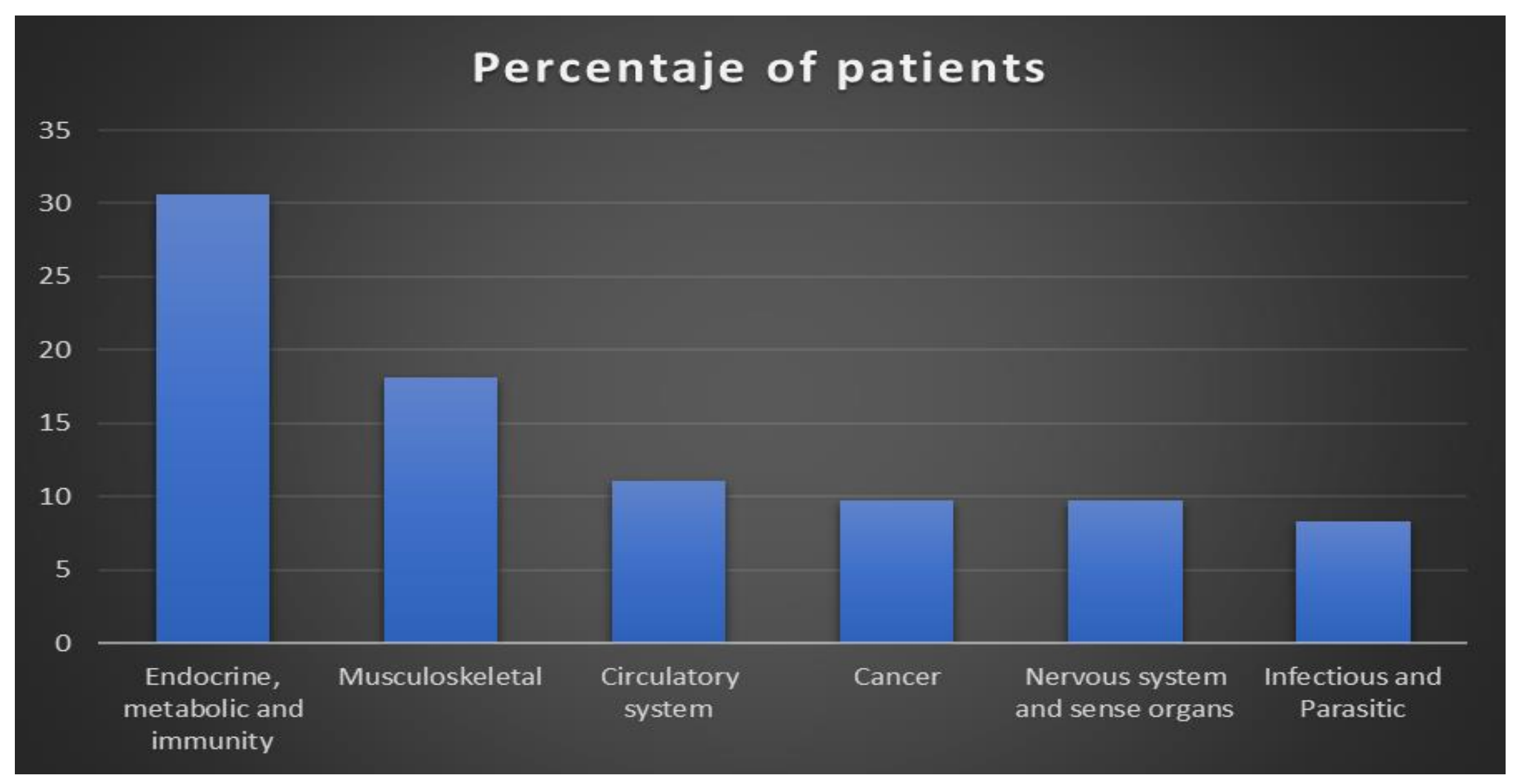

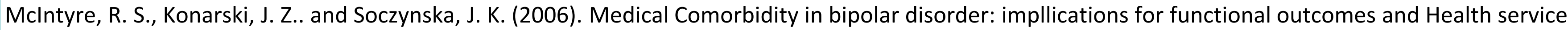
utilization. Psychiatric Services, 57-1140

Perron, B. E. Howard, M. O. and Nienhuis, J. K (2009). Prevalence and burden of general medical conditions among adults with bipolar I disorder: results from the National Epidemiologic Survey on Alcohol and Related Conditions. Journal of Cllinical Psychiatry, $70-1407$. 